\title{
PREPARATION AND CHARACTERIZATION OF HYDROXYAPATITE BASED NANO-COMPOSITE BIOMORPHIC IMPLANTS
}

\section{RÉKA BARABÁS ${ }^{a}$, MELINDA RIGÓa, MARGIT ENISZNÉ-BÓDOGHº, CORINA MOISA ${ }^{\mathrm{c}}$, OANA CADAR ${ }^{\mathrm{d} *}$}

\begin{abstract}
The aim of this study was the preparation and characterization of different biomorphic implants based on calcined cattle bones coated with hydroxyapatite (Hap) based nanocomposites in different ratios. For comparison, molded nanocomposites were also produced as biomorphic implants. The obtained nanocomposite/implants were characterized using $X$ ray diffraction, light microscopy and scanning electron microscopy, BrunauerEmmett-Teller surface area and apparent porosity. The release of $\mathrm{Ca}$ and $\mathrm{P}$ in simulated body fluid was monitored by X-ray fluorescence. The adsorption capacity and extended-release dosage of implants were investigated with ibuprofen, an anti-inflammatory drug, by UV-VIS spectroscopy. The highest adsorption efficiency and stability were obtained for sintered (S) (Hap-) and 20\% gelatin (G) nanocomposite (Hap-20G-S) and bone parts coated with Hap-S and Hap-20G-S nanocomposite, respectively. The best results (high adsorption efficiency and slow release - low desorption capacity) were obtained for molded Hap-20G-S composite, without bone. In summary, the cattle bones with hydroxyapatite coatings show great promise in production of inexpensive and patient-specific bone implants.
\end{abstract}

Keywords: biomorphic implants, hydroxyapatite, gelatin, carbon nanotubes, ibuprofen

a Babeș-Bolyai University, Faculty of Chemistry and Chemical Engineering, Hungarian Line of Study, 11 Arany Janos Street, RO-400028 Cluj-Napoca Romania

b University of Pannonia, Institute of Materials Engineering, 10 Egyetem Street, $\mathrm{H}-8200$ Veszprem, Hungary

c University of Oradea, Medicine and Pharmacy Faculty, Department of Pharmacy, 29 Nicolae Jiga Street, RO-410028, Oradea, Romania

d INCDO-INOE 2000, Research Institute for Analytical Instrumentation, 67 Donath Street, RO400293 Cluj-Napoca, Romania

* Corresponding author: oana.cadar@icia.ro 


\section{INTRODUCTION}

The biocompatibility of orthopedic or dental metallic implants can be significantly enhanced using bioceramics as coating materials [1]. The biomorphic implants minimize the bone resorption, as well as inflammations using coatings containing anti-inflammatory drugs such as ibuprofen (IBU) or ketoprofen [2]. Also, these biomorphic materials can improve bone regeneration [3]. Due to their similar behaviors to bones in terms of elasticity, lightness and strength, the natural woods were used for biomorphic implants [4]. Also, the animal bones such as cattle bones could be a better alternative in order to evaluate the bone-implant interactions [5]. Hydroxyapatite (Hap) is a naturally occurring mineral form of calcium apatite and has been identified as the major mineral constituent of bones and teeth [6, 7]. Hap is a non-toxic, non-allergenic, non-mutagenic, osteoconductive, bioactive and biodegradable material with applications like coatings on different types of implants, carriers for drug delivery systems [8, 9], water purification, chromatography, food industry, gene therapy and anti-cancer drugs [10]. The synthesized Hap (molar ratio of $\mathrm{Ca} / \mathrm{P}=1.67$ ) has similar chemical composition and crystal structure to Hap in the human skeletal system. Recently, great attention has been paid to the ions ( $\mathrm{Na}, \mathrm{Mg}, \mathrm{K}, \mathrm{Sr}, \mathrm{Zn}, \mathrm{Ba}, \mathrm{Cu}, \mathrm{Al}, \mathrm{Fe}, \mathrm{F}, \mathrm{Cl}$ and $\mathrm{Si}$ ) substituted Hap in order to create chemical compositions with more similarity to natural bone mineral $[9,11]$. Furthermore, the mechanical properties of Hap can be improved by adding carbon nanotubes (CNTs), but their toxicity still represents a major challenge, numerous conflicting studies demonstrating both toxic and nontoxic behavior $[12,14]$. The synthesized CNTs tend to agglomerate due to van der Waals forces and can be well-dispersed in water or organic solvents, without physical or chemical modification $[15,16]$. CNTs were discovered by Jijima in 1991 and can be categorized into single-wall carbon nanotubes (SWCNTs), double-wall carbon nanotubes (DWCNTs) and multi-wall carbon nanotubes (MWCNTs) $[13,16]$. Besides Hap, the human skeletal system also contains gelatin $(G)$, a natural polypeptide with biocompatible, biodegradable and non-immunogenic characteristics. $\mathrm{G}$ can be obtained from animal bones collagen by hot water extraction, followed by sol-gel transformation at $35^{\circ} \mathrm{C}$ [17]. Due to their high specific surface and biocompatibility, G-CNT-Hap nanohybrids can be used as coatings and for drug delivery systems [17].

IBU is a non-steroidal anti-inflammatory drug; racemic IBU and Senantiomer are used to reduce inflammations, fever and mild to moderate pain by blocking enzymes and protein in the human body [18, 19]. IBU has been frequently employed as a model drug for sustained/controlled release due to its short biological half-life $(2 \mathrm{~h})$, suitable molecule size $(0.6-1.0 \mathrm{~nm})$ 
and good pharmacological activity [20]. The absorption of IBU on activated carbon surface is an endothermic process, but the adsorption mechanism is not completely elucidated. IBU can form aggregates before the adsorption [21]. The time of drug release depends on the strength of hydrogen bonding between drug and carrier molecules, as well as the molecular size of drug $[8,9]$.

Various studies reported Hap coating on metallic (orthopedic or dental) implants due to their chemical and mechanical properties closer to those of human bone, good biocompatibility; however, the release of ions in the blood stream could be harmful to the patient, inducing allergic, inflammatory or carcinogenic responses [22]. The internal structure and surface properties of systems facilitates the therapeutic activity by maintaining drug release over the minimum inhibitory concentration for a long period of time. Furthermore, the rough structure of the scaffolds facilitates the drug penetration through [23].

The synthesis reproducibility, the quality and properties of the reaction product could be improved by a continuous monitoring and a precise control using loT (Internet of Things), a virtually connected network of physical devices through the infrastructure of Internet [24]. IoT is appropriate for automating the chemical procedures and to use the data collected from experiments, being an emerging, low cost and easy-to-use method.

The aim of this study was the production and characterization of biomorphic implants consisting in cattle bones coated with new Hap-based nanocomposites (NCs). For comparison, molded NCs were also produced and characterized. The proposed implants (Hap coatings on a material with very similar structure to those of human bone) have good potential as they can exploit the biocompatible and bonding properties of Hap, while using the mechanical properties of substrate (animal bone). Furthermore, these materials can be used to stimulate bone regeneration or to fill defects in bone [25]. The adsorption and desorption properties of these samples were also investigated by using IBU as an anti-inflammatory agent.

\section{RESULTS AND DISCUSSION}

\section{X-ray diffraction (XRD)}

The characteristic lines of pure Hap (JSPDS file No. 09-432) were observed in the XRD spectrum of the sintered cattle bone powders (Figure 1). 


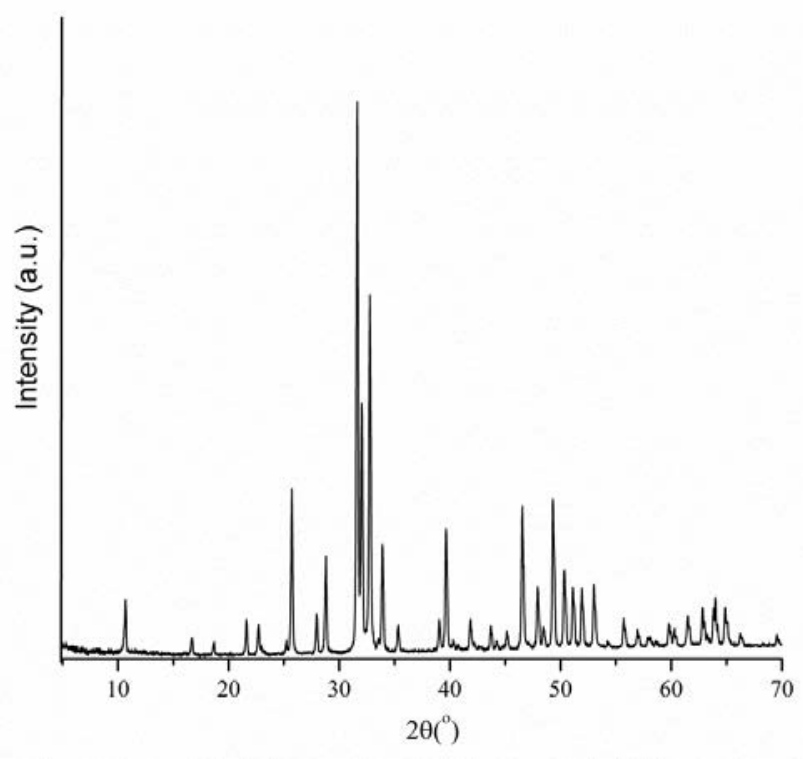

Figure 1. XRD patterns of Hap of the sintered bones.

\section{Thermal analysis}

The thermal analysis of the sintered samples at $900{ }^{\circ} \mathrm{C}$ revealed no significant weight loss or exothermic/endothermic effects for decomposition or other transformation processes, while for dried samples at $105{ }^{\circ} \mathrm{C}$, the combustion of fMWCNT between 400 and $600^{\circ} \mathrm{C}$ was observed [12].

\section{Apparent porosity}

The apparent porosity $(P)$ of samples can influence their mechanical strength, presence of structural defects and permeability [26].

Figure 2 shows that the solid bone part coated with Hap-20G-D exhibits the highest apparent porosity, but it has to be taken into consideration that the sample was dried and $G$ could potentially form hydrogen bonds with surroundings water molecules. $G$ is a hydrophylic substance and the threedimensional structure is stabilized by both $-\mathrm{NH}$ and $-\mathrm{COOH}(-\mathrm{OH})$ groups which can form hydrogen bonds with other $G$ chains and water molecules [27]. The dried bone-coated samples had the highest apparent porosity. Sintered samples obviously had lower apparent porosity because the sintering process decreases the porosity of materials; the number of $\mathrm{OH}$-groups is also lower due to the thermal treatment of the samples. 

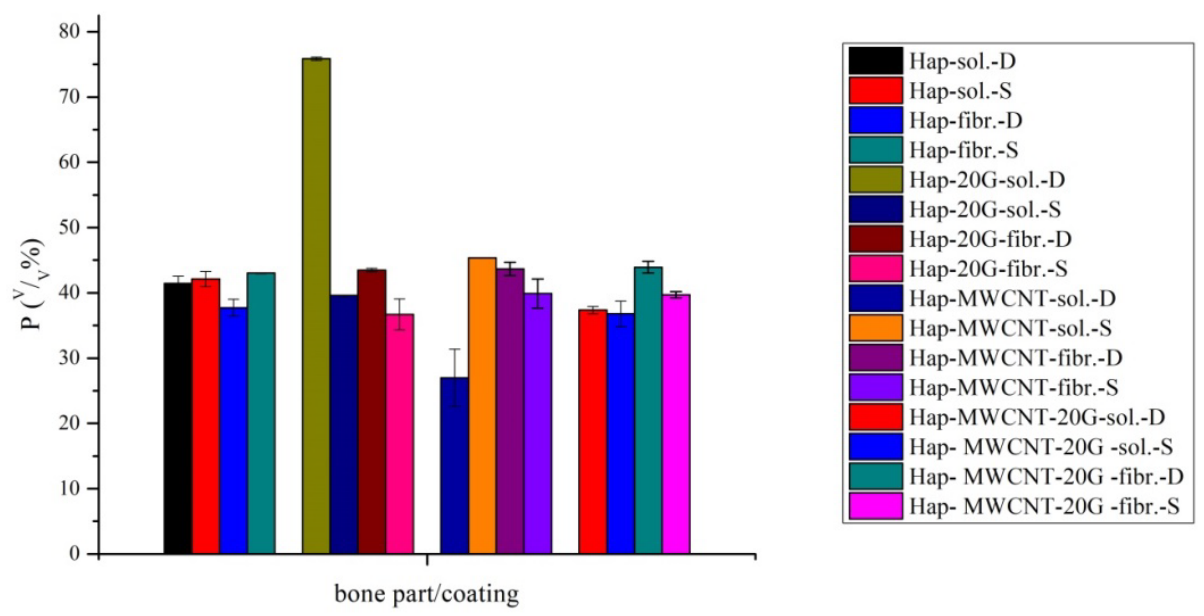

Figure 2. Apparent porosity of Hap based NCs - coated cattle bones.

In the case of molded NCs, dried samples exhibited the highest apparent porosity (Figure 3); this effect can be attributed not only to the opened pores, but to the hydrogen bonds between $-\mathrm{OH}$ groups and water used for measurement [28]. In the case of samples containing CNT, the apparent porosity increased. The highest porosity was achieved by the dried, molded NCs containing three components: Hap, CNT and G. Among the sintered samples, the Hap-MWCNT-S sample had the highest (and stable) porosity. The porosity measurements revealed higher porosity for NCs-coated cattle bones comparing to molded NCs. These results are in good agreements with SEM images.

\section{Specific surface area (BET)}

According to BET measurements, the dried NCs (Hap-MWCNT-D $206 \mathrm{~m}^{2} / \mathrm{g}$ ) had larger specific surface area than the sintered NCs (HapMWCNT-S $-7.20 \mathrm{~m}^{2} / \mathrm{g}$ ). A possible explanation for this difference is that MWCNTs were combusted from the structure during sintering at $900{ }^{\circ} \mathrm{C}$ resulting in lower specific surface area [12].

In the case of dried samples containing three components (Hap, MWCNT and $\mathrm{G}-119 \mathrm{~m}^{2} / \mathrm{g}$ ), the specific surface area was lower than in the case of samples containing two components, which can be explained by the different interactions between the functional groups of $G$ and Hap. 

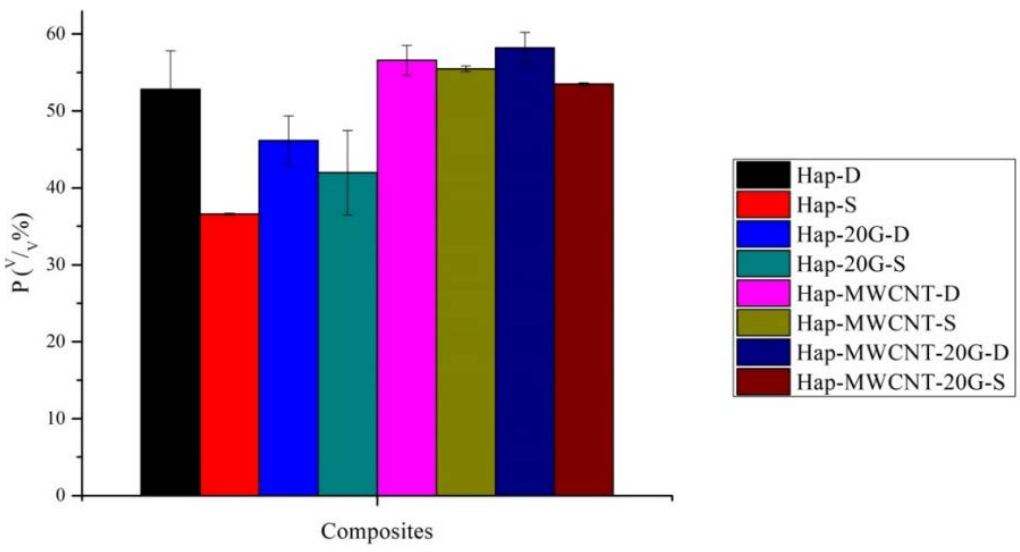

Figure 3. Apparent porosity of molded NCs.

\section{X-ray Fluorescence (XRF)}

$\mathrm{XRF}$ was used to monitor $\mathrm{Ca}$ and $\mathrm{P}$ content (mass change due to the ion transfer). The dried samples had a mass loss, but the sintered samples had a mass increase, because a new Hap layer was formed on their surface from the SBF (Simulated Body Fluid) [29]. The dried samples were not stable, their weight loss could be explained by the partial dissolution of the samples in the SBF. In the case of bone coated samples (black and red columns), the solid part did not really change, but the fibrous parts' weight increases due to the new Hap layer deposition in the pores (Figure 4).

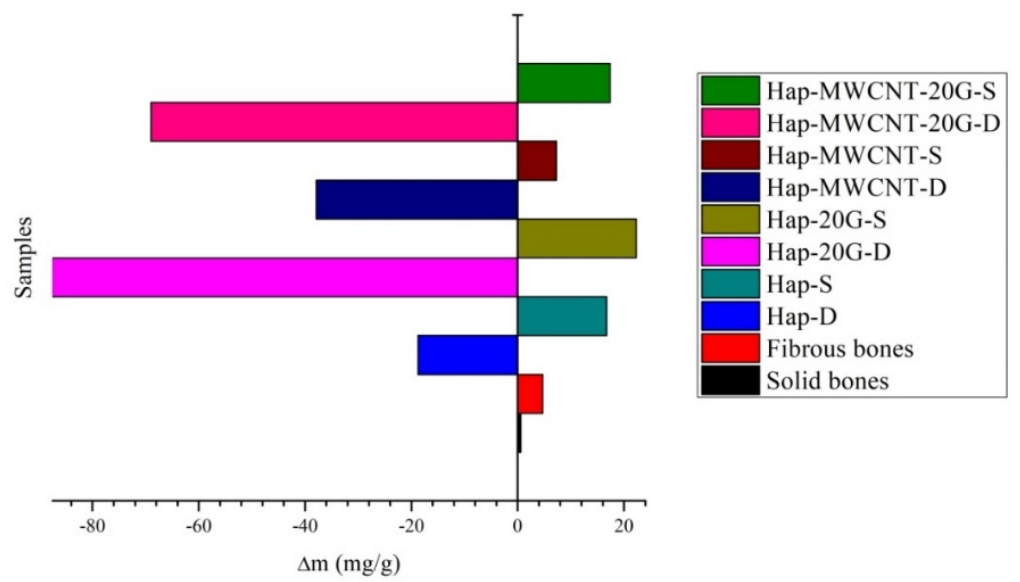

Figure 4. Mass change of NCs after 7 days of soaking in SBF. 
Based on these results, it can be concluded that the behavior of Hapbased NC in SBF solution strongly depends on the heat treatment of the samples: for dried samples, occurred a partial dissolution, while on the surface of the sintered samples, a new Hap layer formed.

\section{Scanning electron microscopy (SEM)}

SEM images of Hap based NCs - coated cattle bones and molded NCs are presented in Figures 5 and 6.

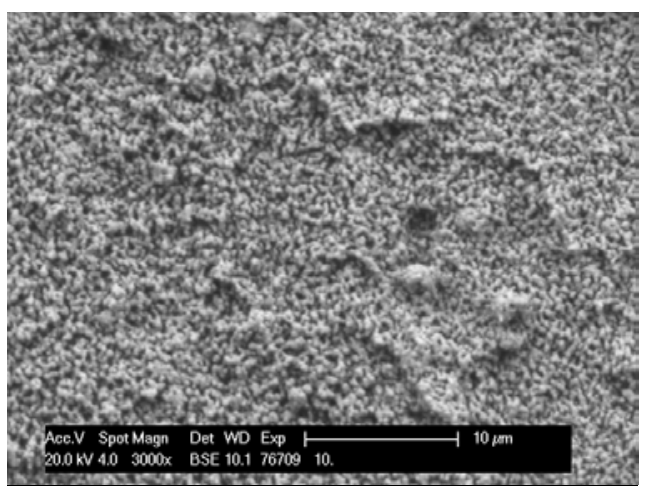

Hap-MWCNT-sol.-S

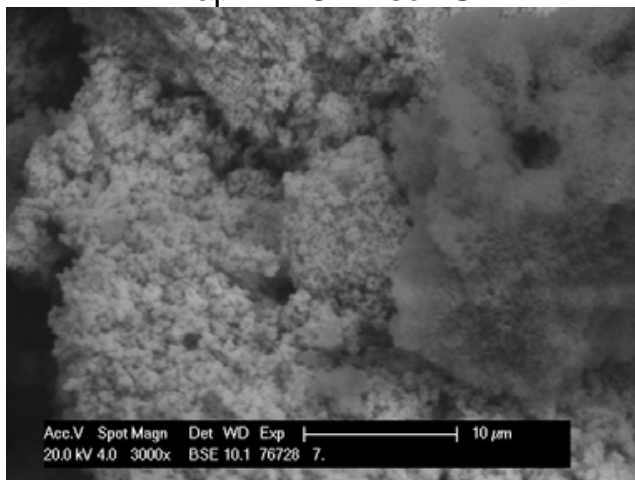

Hap-20G-fibr.-S

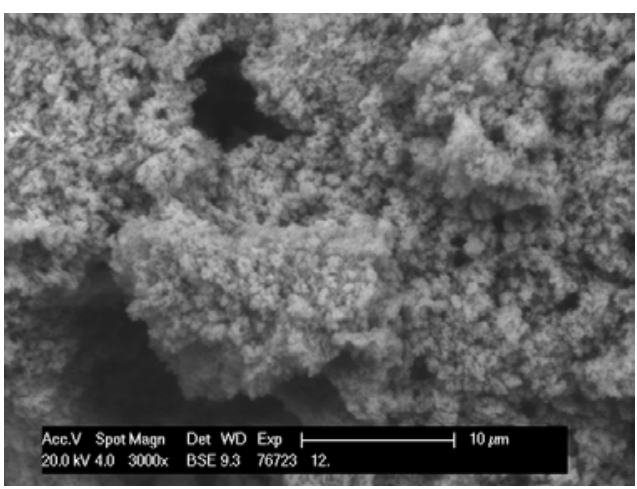

Hap-MWCNT-fibr.-S

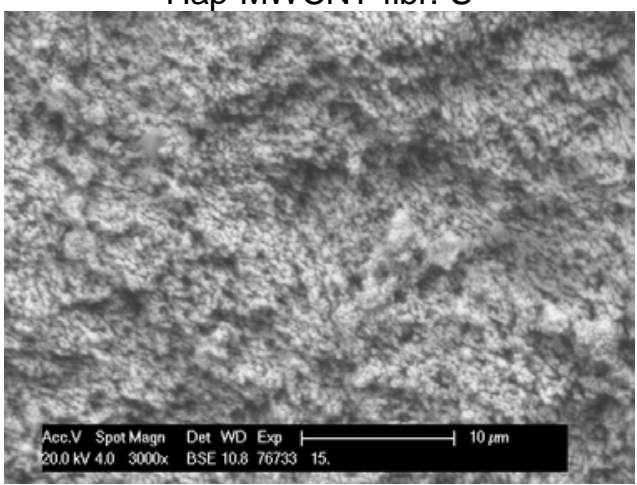

Hap-MWCNT-20G-fibr.-S

Figure 5. SEM images of Hap based NCs - coated cattle bones.

The SEM images revealed a difference in porosity: Hap based NCs used as coatings for cattle bones are more porous, while the molded NCs (no substrate) are compact with low porosity. Hap based NCs used as coatings for cattle bones mimic the natural bone surface structure favoring the growth of neighbouring tissues in the coating pores. 


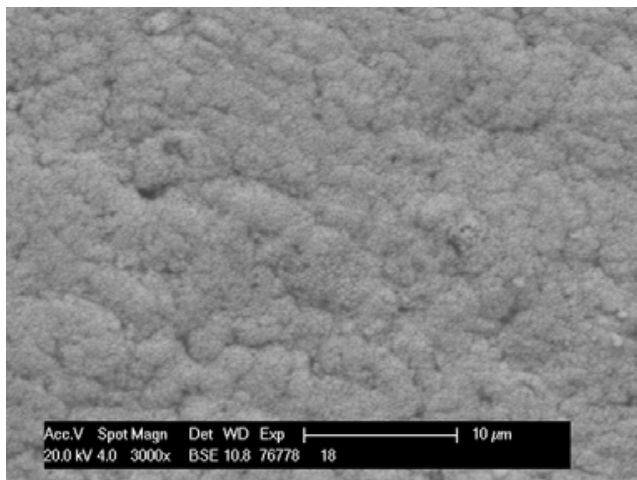

Hap-S

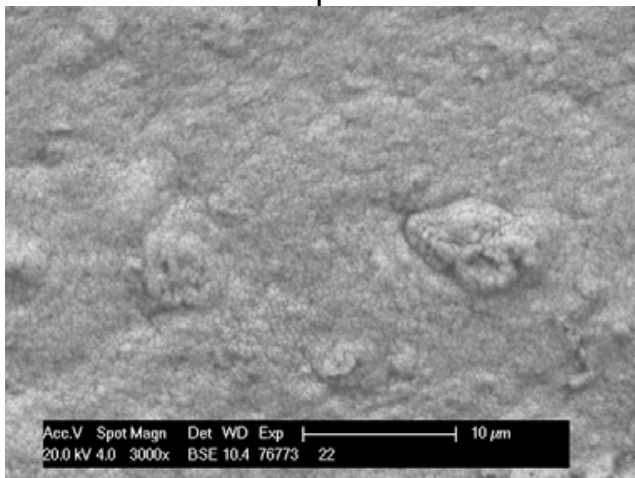

Hap-MWCNT-S

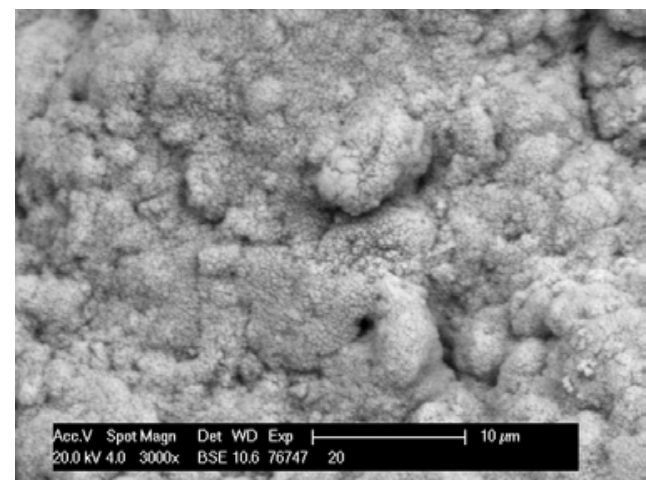

Hap-20G-S

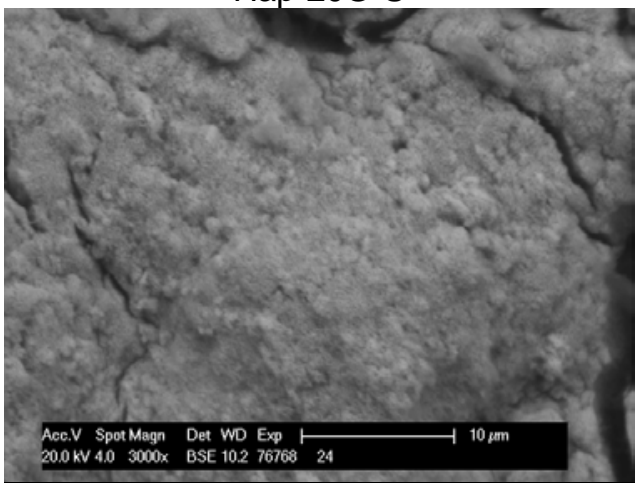

Hap-MWCNT-20G-S

Figure 6. SEM images of molded NCs.

\section{Light microscopy}

The light microscopy images of Hap based NCs - coated cattle bones are shown in Figure 7, revealing the heterogenous character of dried samples. In the case of sintered samples, the light microscopy images confirm that the MWCNTs were combusted between 400 and $600^{\circ} \mathrm{C}$ [12].

\section{Adsorption studies}

In this study, four types of coatings and two types of cattle bones (fibrous and solid) were obtained, resulting four groups of samples. In case of NCs - coated cattle bones, the adsorption capacity depended on the following parameters: bone part type, coating composition and post-heat treatment (Figure 8). 


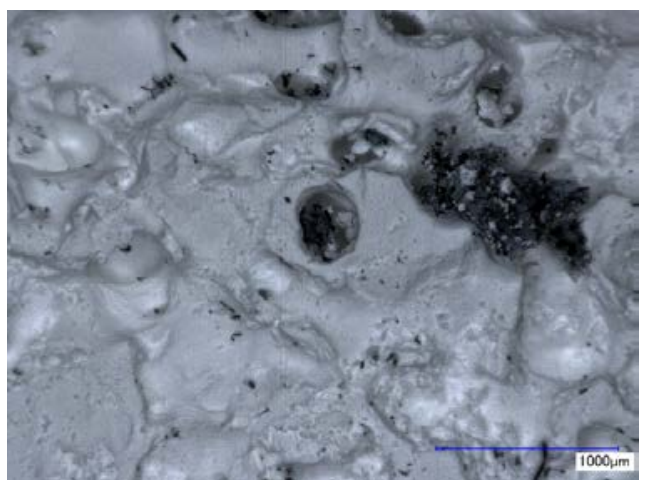

Hap-MWCNT-sol.-D

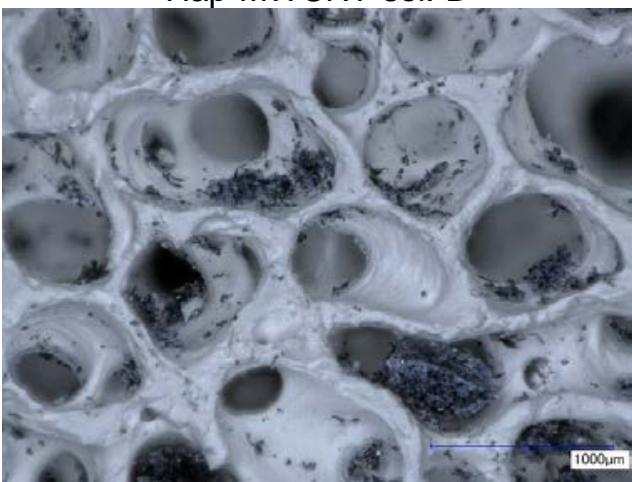

Hap-MWCNT-20G-fibr.-D

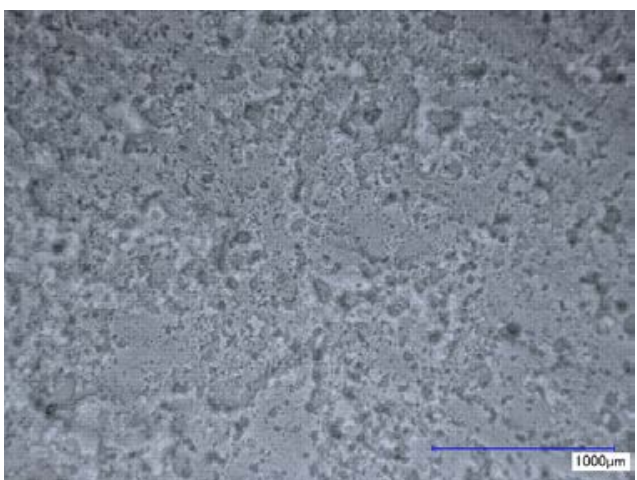

Hap-MWCNT-sol.-S

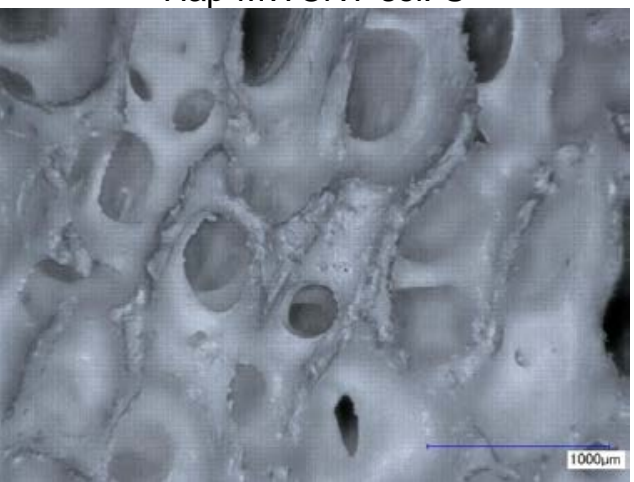

Hap-MWCNT-20G-fibr.-S

Figure 7. Light microscopy images of Hap based NCs - coated cattle bones.

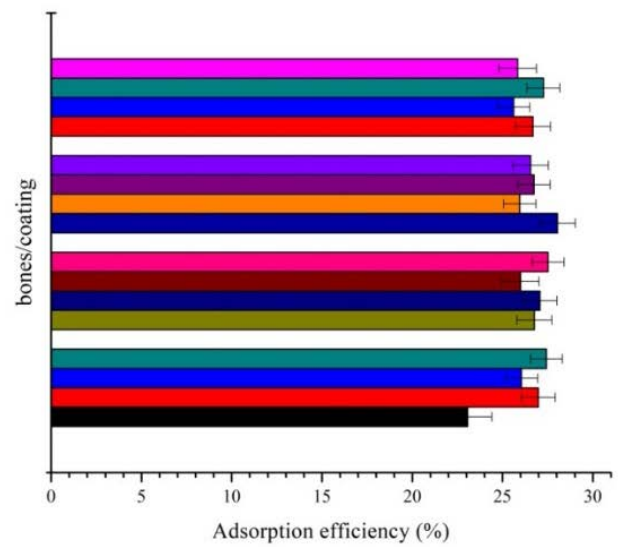

\begin{tabular}{|l|l|}
\hline & Hap- MWCNT-20G -fibr.-S \\
& Hap- MWCNT-20G -fibr.-D \\
& Hap- MWCNT-20G -sol.-S \\
& Hap-MWCNT-20G-sol.-D \\
& Hap-MWCNT-fibr.-S \\
& Hap-MWCNT-fibr.-D \\
\hline & Hap-MWCNT-sol.-S \\
\hline & Hap-MWCNT-sol.-D \\
Hap-20G-fibr.-S \\
Hap-20G-fibr.-D \\
Hap-20G-sol.-S \\
Hap-20G-sol.-D \\
Hap-fibr.-S \\
Hap-fibr.-D \\
Hap-sol.-S \\
Hap-sol.-D \\
\hline
\end{tabular}

Figure 8. Adsorption efficiency ( $\eta$ ) of Hap based NCs - coated cattle bones. 
The highest adsorption efficiency of every group was selected (Table 1).

Table 1. The highest adsorption efficiency of Hap based NCs - coated cattle bones.

\begin{tabular}{|c|c|c|}
\hline $\begin{array}{c}\text { Type of composite used for } \\
\text { coating (group of sample) }\end{array}$ & $\begin{array}{c}\text { The highest adsorption efficiency } \\
\text { (type of sample) }\end{array}$ & $\begin{array}{c}\text { Adsorption efficiency } \\
(\%)\end{array}$ \\
\hline Hap & Hap-fibr.-S & 27.4 \\
\hline Hap-20G & Hap-20G-fibr.-S & 27.5 \\
\hline Hap-MWCNT & Hap-MWCNT-sol.-D & 28.0 \\
\hline Hap & Hap-MWCNT-20G-fibr.-D & 27.3 \\
\hline
\end{tabular}

BET analyses also confirmed that Hap-MWCNT had the highest specific surface area. XRF analyses indicated that the dried NCs were partially soluble in SBF, but the sintered samples were stable in SBF. As a result, although the Hap-MWNCT-sol.-D sample had the highest adsorption efficiency, it could be not considered stable in SBF. After sintering (HapMWNT-sol.-S), the CNTs were combusted and the specific surface area of the samples decreased.

Both samples were stable and had high adsorption efficiency: Hapfibr.-S (27.4\%) and Hap-20G-fibr.-S (27.5\%). So, the adsorption efficiency also depends on the cattle bone structure: as expected, the fibrous samples had higher adsorption efficiency than the solid ones.

In the case of molded NCs, Hap-MWCNT-D exhibited the highest adsorption efficiency (28.4\%) (Figure 9). XRF analyses showed that NCs without sintering were not stable, the highest adsorption efficiency was achieved by the samples: Hap-S (28.1\%) and Hap-20G-S (27.9\%).

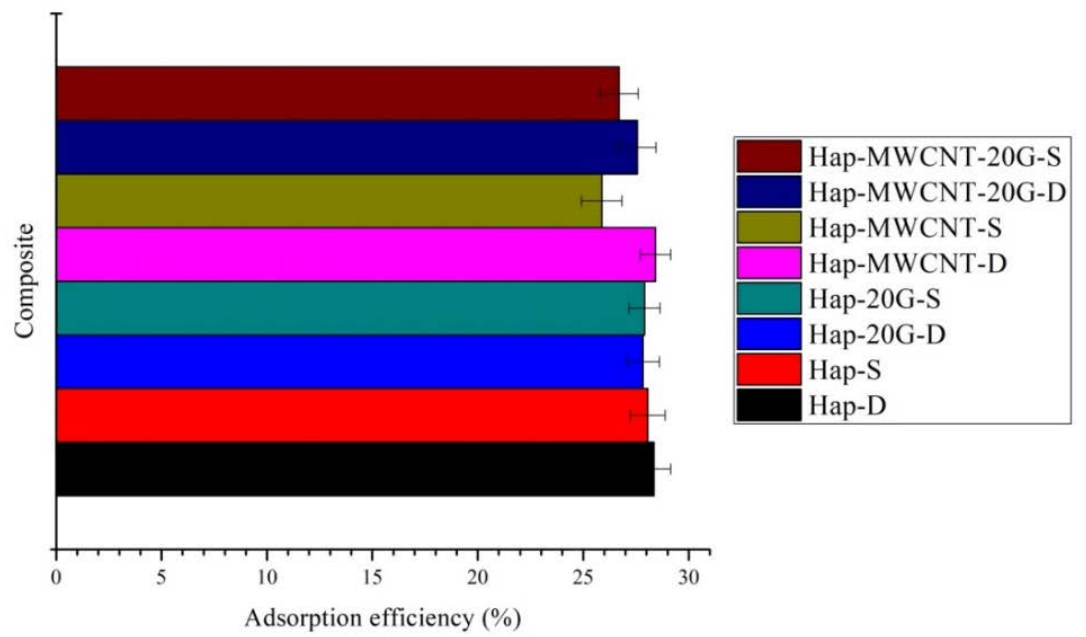

Figure 9. Adsorption efficiency ( $\eta$ ) of molded NCs. 
The adsorption efficiency values in the case of dried and sintered samples were close to each other, so it can be concluded that the sintering process did not reduce essentially the adsorption capacity of the samples.

The highest adsorption efficiency and stability were obtained by the Hap-S and Hap-20G-S molded NCs and bone parts with Hap-S and Hap20G-S NCs coatings. So, the same NC showed the most appropriate results in both cases.

\section{Desorption studies}

In the case of cattle bones-coated NCs, the highest IBU release were observed for samples with the highest adsorption efficiency (Figure 10). A scale break was introduced, because the values between 240 and 600 min remained quasi-constant. Based on the adsorption capacity and stability in SBF, the IBU release was studied for Hap-fibr.-S and Hap-20G-fibr samples (Table 2). After $24 \mathrm{~h}$, similar results were obtained for Hap-fibr.-S (2.16\%) and Hap-20G-fibr.-S (2.20 \%).

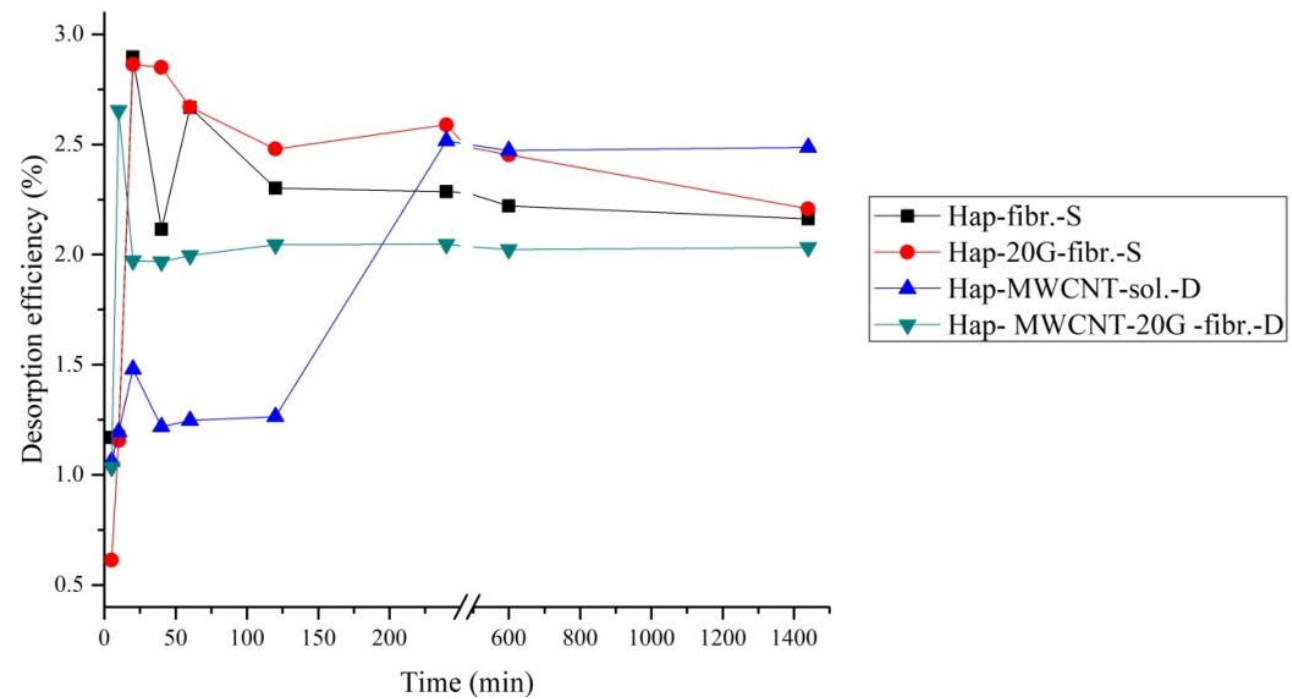

Figure 10. IBU release from Hap based NCs - coated cattle bones.

Table 2. IBU release of four cattle bone - coated samples.

\begin{tabular}{|c|c|c|}
\hline Sample & Adsorption efficiency (\%) & Desorption efficiency (\%) \\
\hline Hap-fibr.S & 27.4 & 2.16 \\
\hline Hap-20G-fibr.-S & 27.5 & 2.20 \\
\hline Hap-MWCNT-sol.-D & 28.0 & 2.49 \\
\hline Hap-MWCNT-20G-fibr-D & 27.3 & 2.03 \\
\hline
\end{tabular}


Based on XRF and adsorption (stability in SBF) results, Hap-S, Hap20G-S, Hap-MWCNT-S, and Hap-MWCNT-20G-S were chosen as relevant to investigate the desorption efficiency (Figure 11). A scale break between 600 and 1440 min on $x$-axis was introduced, because the values at 120, 240 and 360 min remained quasi-constant. Hap-20G-S had the slowest IBU release (retard effect), after $24 \mathrm{~h}$, only $1.57 \%$ of IBU was desorbed.

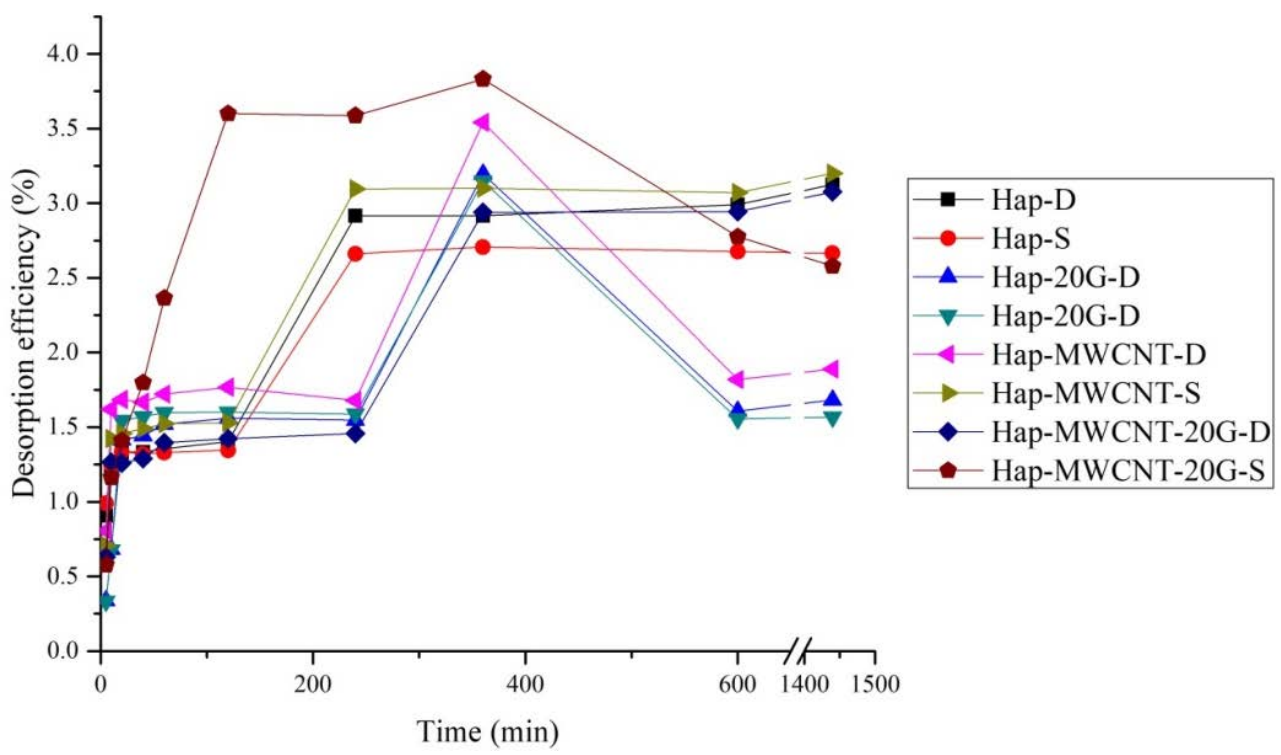

Figure 11. Desorption efficiency of molded NCs.

Regarding the desorption process, the difference in behavior of bone and boneless samples can be explained by the different surface morphology on which IBU was adsorbed. The different surface morphology was also confirmed by SEM images.

For the molded NCs, a rapid decrease of desorption after 5 to $10 \mathrm{~h}$ was observed, after which the process stabilized and increased steadily. This variation can be attributed to equilibrium processes in the solvent, desorption being an oscillating process until reaching equilibrium [35].

Table 3 shows a comparison between the adsorption and desorption efficiency of both types of samples (molded NCs and cattle bones with coating). 
Table 3. The best results for IBU release - molded NCs.

\begin{tabular}{|c|c|c|}
\hline Sample & Adsorption efficiency (\%) & Desorption efficiency (\%) \\
\hline Hap-fibr.S & 27.4 & 2.16 \\
\hline Hap-20G-fibr.S & 27.5 & 2.21 \\
\hline Hap-S & 28.1 & 2.68 \\
\hline Hap-20G-S & 27.9 & 1.58 \\
\hline Hap-MWCNT-S & 25.9 & 3.20 \\
\hline Hap-MWCNT-20G-S & 26.7 & 2.59 \\
\hline
\end{tabular}

The best results (high adsorption efficiency and slow release - low desorption capacity) were obtained for molded and sintered Hap-20G-S NCs. In the case of Hap based NCs - coated fibrous cattle bones, a low desorption capacity due to the porous character of bones was observed.

\section{CONCLUSIONS}

The purpose of this study was the preparation and characterization of NCs containing Hap, MWCNT and G in different ratios and their application as coatings for cattle bones (solid and fibrous) and for comparison molded NCs were also prepared. In the case of samples dried at $105^{\circ} \mathrm{C}$, the presence of CNTs increased the absorption capacity, while in the case of samples sintered at $900^{\circ} \mathrm{C}, \mathrm{CNTs}$ were combusted at $400-600^{\circ} \mathrm{C}$, resulting in a decrease of the absorption capacity. However, the sintered samples were more stable in SBF than dried ones. As a result, future studies to find the optimal sintering temperature to provide both the presence of CNTs and a good stability of samples in SBF are required. HAP-S and Hap-20G-S samples (NCs - coated cattle bones and molded NCs) presented high adsorption capacity. According to porosity measurements and SEM images, the NCs - coated cattle bones exhibited higher porosity than molded NCs. Comparing the obtained results for NCs - coated cattle bones and molded NCs, it can be concluded that the quality of coating depends not only on the coated material but also on the quality and structure of support (solid or fibrous). The studied NCs are materials with promising applications in engineering of bone implants due to their excellent chemical and structural properties.

\section{EXPERIMENTAL SECTION}

\section{Materials}

All reagents were of analytical grade (Merck, Germany) and used without further purification. Pepsin from porcine gastric mucosa (P7125) and trypsin from porcine pancreas (T7409) were purchased from Sigma Aldrich 
(USA). The multiwalled carbon nanotubes (MWCNTs) were synthesized at $700{ }^{\circ} \mathrm{C}$ by chemical vapor deposition process (purity $\sim 90 \mathrm{wt} . \%$, average diameter 10-20 nm, length $>50 \mu \mathrm{m}$ ) [31].

\section{Preparation of Hap NC}

The cattle leg bones Alfa-Lox Bt., Hungary were calcined at $950^{\circ} \mathrm{C}$ for 1 $\mathrm{h}$ to remove the organic part. The calcined bones were cut into pieces of approx. 1.0-1.5 cm length, boiled with trypsin and pepsin and washed with water. The protein-free bones were cleaned with phosphoric acid $85 \%$ and water.

The Hap-based NCs (Table 1) were prepared by precipitation in a similar way to the synthesis of pure Hap [12]. The solutions of $0.5 \mathrm{~mol} / \mathrm{L} \mathrm{Ca}\left(\mathrm{NO}_{3}\right)_{2}$ and $0.3 \mathrm{~mol} / \mathrm{L}\left(\mathrm{NH}_{4}\right)_{2} \mathrm{HPO}_{4}$ were prepared in order to meet the stoichiometric $\mathrm{Ca} / \mathrm{P}=$ 1.67. $\mathrm{G}$ or/and MWCNTs were added to a $0.5 \mathrm{~mol} / \mathrm{L} \mathrm{Ca}\left(\mathrm{NO}_{3}\right)_{2}$ solution and the $\mathrm{pH}$ was adjusted to 11 by adding a $25 \%$ ammonia solution, under constant stirring, at room temperature, resulting solution $\mathrm{A}$. After the $\mathrm{pH}$ adjustment, a 0.3 $\mathrm{mol} / \mathrm{L}\left(\mathrm{NH}_{4}\right)_{2} \mathrm{HPO}_{4}$ solution was added dropwise to solution $\mathrm{A}$ under magnetic stirring, at room temperature. The resulted solution was mixed for $22 \mathrm{~h}$ and the precipitate was filtered and washed with distilled water.

The process parameters were anytime/anywhere monitored using an in-house "IoT-smartbox" equipped with temperature sensor, heating element, $\mathrm{pH}$-meter and peristaltic pump. The main advantages of "IoT-smartbox" are: (i) the safety-related control by automatically turned off if the critical temperature is reached or sending an alert message through SMS and email (in "safe zone") and (ii) the possibility to track the history of the process.

\section{Preparation of Hap based NCs - coated cattle bones}

The solid and fibrous parts of bones were placed under vacuum (680 $\mathrm{mmHg}$ ) for $15 \mathrm{~min}$ to remove the air pollutants. Then, each bone part (approx. $1 \mathrm{~cm}$ ) was soaked in a $1 \mathrm{~g} \mathrm{~cm}^{-3}$ mixture (composite/ethanol), for $30 \mathrm{~min}$. The resulted samples were: (i) only dried at $105^{\circ} \mathrm{C}$ for $24 \mathrm{~h}$ (D) or (ii) dried at 105 ${ }^{\circ} \mathrm{C}$ for $24 \mathrm{~h}$ and sintered at $900{ }^{\circ} \mathrm{C}$ for $1 \mathrm{~h}$ (S) (Figure 12, Table 4).

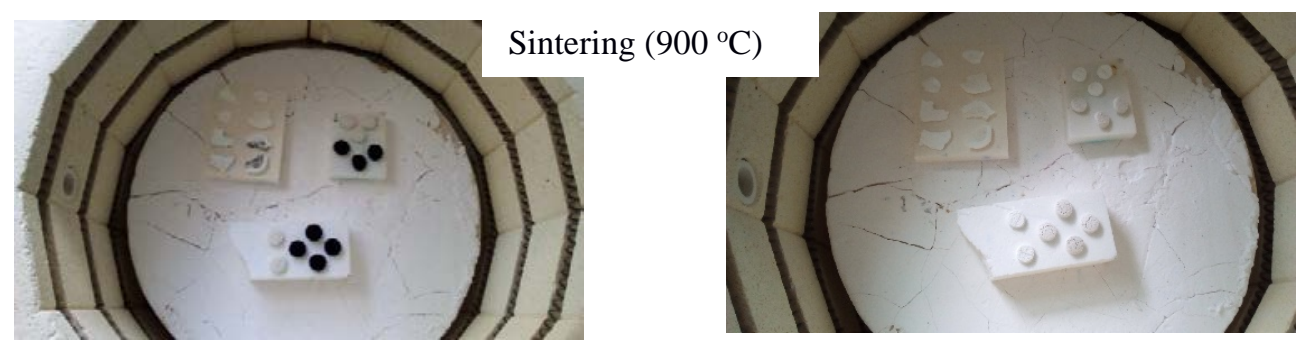

Figure 12. Dried/sintered Hap based NCs - coated cattle bones and molded NCs. 


\section{Preparation of molded Hap-based NCs}

For comparison, the obtained Hap-based NCs were molded using round shape silicone forms with diameter of $2 \mathrm{~cm}$, (I) only dried at $105^{\circ} \mathrm{C}$ for $24 \mathrm{~h}(\mathrm{D})$ or (ii) dried at $105{ }^{\circ} \mathrm{C}$ for $24 \mathrm{~h}$ and sintered at $900{ }^{\circ} \mathrm{C}$ for $1 \mathrm{~h} \mathrm{(S)}$ (Table 1).

\section{Adsorption of IBU}

The samples (Hap based NCs - coated cattle bones and molded NCs) were soaked in IBU solution (17 g IBU /L ethanol, the concentration which grants the maximum adsorption capacity) [32]. After adsorption (24 h), the solid parts were separated by centrifugation, rinsed with ethanol and dried at $40-50^{\circ} \mathrm{C}$, for $24 \mathrm{~h}$. The concentration of IBU in the liquid part was investigated using a UV-VIS spectrophotometer at $272 \mathrm{~nm}$. The experiments were carried-out in triplicate. The adsorption efficiency, $\eta_{a}(\%)$, was calculated using Eqs. 1 and 2.

$$
\begin{aligned}
& Q=\frac{m_{a}}{m} \\
& \eta_{a}=Q \times \frac{m}{c_{0} \times V} \times 100
\end{aligned}
$$

where: Q - adsorption capacity (mg/g), $\mathrm{m}_{\mathrm{a}}$ - adsorbed mass of IBU (mg), $\mathrm{m}$ mass of sample $(\mathrm{g}), \mathrm{C}_{\mathrm{o}}$ - initial IBU concentration $(\mathrm{g} / \mathrm{L})$ and $\mathrm{V}$ - volume of IBU solution used for adsorption $(\mathrm{mL})$.

\begin{tabular}{|c|c|c|c|c|c|c|c|}
\hline No & Hap & $\begin{array}{c}\text { fMWCNT } \\
\text { (\% wt.) }\end{array}$ & $\begin{array}{c}\mathbf{G} \\
\text { (\% wt.) }\end{array}$ & Composite & $\begin{array}{l}\text { Bone } \\
\text { type }\end{array}$ & Operation & $\begin{array}{c}\text { Implant type } \\
\text { (abbreviations) }\end{array}$ \\
\hline \multirow{4}{*}{1} & \multirow{4}{*}{ Hap } & \multirow{4}{*}{0} & \multirow{4}{*}{0} & \multirow{4}{*}{ Hap } & \multirow{2}{*}{ Solid } & Drying & Hap-sol.-D \\
\hline & & & & & & Sintering & Hap-sol.-S \\
\hline & & & & & \multirow{2}{*}{ Fibrous } & Drying & Hap-fibr.-D \\
\hline & & & & & & Sintering & Hap-fibr.-S \\
\hline \multirow{4}{*}{2} & \multirow{4}{*}{ Hap } & \multirow{4}{*}{0} & \multirow{4}{*}{20} & \multirow{4}{*}{ Hap-20G } & \multirow{2}{*}{ Solid } & Drying & Hap-20G-sol.-D \\
\hline & & & & & & Sintering & Hap-20G-sol.-S \\
\hline & & & & & \multirow{2}{*}{ Fibrous } & Drying & Hap-20G-fibr.-D \\
\hline & & & & & & Sintering & Hap-20G-fibr.-S \\
\hline \multirow{4}{*}{3} & \multirow{4}{*}{ Hap } & \multirow{4}{*}{10} & \multirow{4}{*}{0} & \multirow{4}{*}{$\begin{array}{l}\text { Hap- } \\
\text { MWCNT }\end{array}$} & \multirow{2}{*}{ Solid } & Drying & Hap-MWCNT-sol.-D \\
\hline & & & & & & Sintering & Hap-MWCNT-sol.-S \\
\hline & & & & & \multirow{2}{*}{ Fibrous } & Drying & Hap-MWCNT-fibr.-D \\
\hline & & & & & & Sintering & Hap-MWCNT-fibr.-S \\
\hline \multirow{4}{*}{4} & \multirow{4}{*}{ Hap } & \multirow{4}{*}{10} & \multirow{4}{*}{20} & \multirow{4}{*}{$\begin{array}{l}\text { Hap- } \\
\text { MWCNT- } \\
20 G\end{array}$} & \multirow{2}{*}{ Solid } & Drying & Hap-MWCNT-20G-sol.-D \\
\hline & & & & & & Sintering & Hap-MWCNT-20G-sol.-S \\
\hline & & & & & \multirow{2}{*}{ Fibrous } & Drying & Hap-MWCNT-20G-fibr.-D \\
\hline & & & & & & Sintering & Hap-MWCNT-20G-fibr.-S \\
\hline
\end{tabular}

Table 4. Synthesized Hap-based NCs - coated cattle bones. 


\section{Desorption of IBU}

The release of IBU was investigated by soaking each sample in $20 \mathrm{~mL}$ $\mathrm{SBF}(\mathrm{pH}=7.4)$ at room temperature. SBF was prepared according to Kokubo method [33, 34]. $2 \mathrm{~mL}$ sample was removed at different time intervals, $\mathrm{t}(5,10$, $20,30,60,120,240,360,600$ and $1440 \mathrm{~min}$ ) and immediately replaced with an equal volume of fresh SBF. The amount of IBU released was measured using a UV-VIS spectrophotometer at $224.5 \mathrm{~nm}$. The experiments were carried-out in triplicate. The desorption efficiency, $\eta_{d}(\%)$, was calculated using the amount of IBU adsorbed and the amount of IBU released in SBF.

\section{Characterization}

XRD analysis was performed at room temperature, using a PW3710 X'Pert X-ray diffractometer (Philips, Nederlands), operating at $40 \mathrm{kV}, 30 \mathrm{~mA}$ with CuK $\mathrm{K}_{\alpha}$ radiation $(\lambda=1.542 \AA)$;

The thermal analysis was performed using a Q-1500 D Derivatograph (MOM, Hungary) in Pt crucibles using $\alpha-\mathrm{Al}_{2} \mathrm{O}_{3}$ as inert material, by heating from room temperature to $1000^{\circ} \mathrm{C}\left(5^{\circ} \mathrm{C} / \mathrm{min}\right)$;

The apparent porosity $(P)$, that represents pores accessible to the fluid used in the test, was determined using the Archimedes method based on the principle that a solid with certain bulk immersed in a liquid displaces an amount of liquid equal to the bulk of the liquid when immersed: The following equation was used to calculate the apparent porosity (open pores).

$$
P=\left(\frac{m_{\text {sat }}}{m_{d r}}-\frac{m_{\text {sat }}}{m_{\text {sub }}}\right) \times 100
$$

where: $m_{d r}$ - the mass of the dry sample $(g), m_{\text {sat }}$ - the mass of the sample saturated with liquid $(\mathrm{g})$ and $\mathrm{m}_{\text {sub }}$ - the mass of the sample submerged in liquid (g) [35];

The specific surface area was determined using Asap 2000 equipment (Micromeritics Instruments Inc., USA) from data on nitrogen adsorption; The morphological characteristics of NCs was examined by a XL30-ESEM microscope (Philips, Netherlands) at 20 kV using a Keyence-VHX 2000 Light microscope;

The mass change of NCs was investigated by XRF. The samples were soaked in SBF for 7 days, at $37^{\circ} \mathrm{C}$ and removed after 1,3 and 7 days. The $\mathrm{Ca}$ and $P$ release was monitored using an energy dispersive $X$-ray Fluorescence (XRF) MiniPal4, PANalytical operating at 14 kV, 202 uA. The Ca and P content (mass change due to the ion transfer) was calculated considering the $\mathrm{Ca}$ and $\mathrm{P}$ content of SBF;

The IBU adsorption-desorption studies were performed using a V-560 UV-VIS spectrophotometer (Jasco, Japan). 


\section{ACKNOWLEDGMENT}

M.R. greatly acknowledges the support of the EU Erasmus Programme.

\section{REFERENCES}

1. O. Gryshkov, N.I. Klyui, V.P. Temchenko, V.S. Kyselov, A. Chatterjee, A.E. Belyaev, L. Lauterboeck, D. Iarmolenko, B. Glasmacher, Materials Science and Engineering C, 2016, 68, 143.

2. A.I. Pearce, R.G. Richards, S. Milz, S.G. Pearce, European Cells \& Materials, 2007, 13, 1.

3. Y. Li, S.K. Chen, L. Li, L. Qin, X.L. Wang, Y.X. Lai, Journal of Orthopaedic Research, 2015, 3, 95.

4. G. Filardo, E. Kon, A. Tampieri, R. Cabezas-Rodriguez, A. Di Martino, M. Fini, G. Giavaresi, M. Lelli, J. Martinez Fernandez, L. Martini, J. Ramirez-Rico, F. Salamanna, M. Sandri, S. Sprio, M. Marcacci, Tissue Engineering Part A, 2014, 20, 763.

5. N. Baldini, M. De Sanctis, M. Ferrari, Dental Materials, 2011, 27, 61.

6. D. McConnell, "Carbonate Apatites", pp. 39-47 in Apatite: Its crystal chemistry, mineralogy, utilization, and geologic and biologic occurrences, Springer-Verlag, New York, 1973.

7. T. Sakae, H. Nakada, J.P. LeGeros, Journal of Hard Tissue Biology, 2015, 24 111.

8. K. Tomoda, H. Ariizumi, T. Nakaji, L. Makino, Colloids and Surfaces B, 2010, 76226.

9. M. Cziko, E.S. Bogya, C. Paizs, G. Katona, Z. Konya, A. Kukovecz, R. Barabas, Materials Chemistry and Physics, 2016, 180, 314.

10. C.F. Dai, S.P. Li, X.D. Li, Colloids and Surfaces B, 2015, 136, 262.

11. R. Barabas, M. Cziko, I. Dekany, L. Bizo, E.S. Bogya, Chemical Papers, 2013, 67, 1414.

12. R. Barabas, G. Katona, E.S. Bogya, M.V. Diudea, A. Szentes, B. Zsirka, J. Kovacs, L. Kekedy-Nagy, M., Cziko, Ceramics International, 2015, 41, 12717.

13. S. Dadras, V.M. Farahani, Physica B, 2015, 477, 94.

14. D. Lahiri, S. Ghosh, A. Agarwal, Materials Science and Engineering C, 2012, 32, 1727.

15. A. Abrishamchian, T. Hooshmand, M. Mohammadi, F. Najafi, Materials Science and Engineering C, 2013, 33, 2002.

16. D. Gopi, E. Shinyjoy, M. Sekar, M. Surendiran, L. Kavitha, T.S. Sampath Kumar, Corrosion Science, 2013, 73, 321. 
17. I.K. Yoon, J.Y. Hwang, J.W. Seo, W.C. Jang, H.W. Kim, U.S. Sing, Carbon, 2014, $77,379$.

18. S.D. Bergese, K. Candiotti, S.S. Ayad, S. Soghomonyan, T.J. Gan, Clinical Therapeutics, 2015, 37, 360.

19. T.J. Gan, K. Candiotti, A. Turan, A. Buvanendran, B.K. Philip, E.R. Viscusi, S. Soghomonyan, Clinical Therapeutics, 2015, 37, 368.

20. M. Oner, E. Yetiz, E. Ay, U. Uysal, Ceramics International, 2011, 37, 2117.

21. D. Musmarra, M. Prisciandaro, M. Capocelli, D. Karatza, P., Iovino, S. Canzano, A. Lancia, Ultrasonics Sonochemistry, 2016, 29, 76.

22. B.G.X. Zhang, D.E. Myers, G.G. Wallace, M. Brandt, P.F.M. Choong, International Journal of Molecular Sciences, 2014, 15, 11878.

23. P. Diaz-Rodriguez, A. Perez-Estevez, R. Seoane, P. Gonzalez, J. Serra, M. Landin, ISRN Pharmaceutics, 2013, Article ID 104529, 8 pages.

24. E. Brown, "Who Needs the Internet of Things?", Linux.com, Retrieved 23 October 2016.

25. S.T. Ho, D.W. Hutmacher, Biomaterials, 2006, 27, 1362.

26. P. Spulveda, F.S. Ortega, M.D.M. Innocentini, V.C. Pandolfelli, Journal of the American Ceramic Society, 2000, 83, 3021.

27. A. Duconseille, T. Astruc, N. Quintana, F. Meersman, V. Sante-Lhoutellier, Food Hydrocolloids, 2015, 43, 360.

28. Z.C. Chen, X.L. Zhang, K. Zhou, H. Cai, C.Q. Liu, Advances in Applied Ceramics, 2015,114, 183.

29. P. Sooksaen, N. Pengusawan, S. Karawatthanaworrakul, S. Pianpraditkul, Advances in Condensed Matter Physics, 2015, Article ID 158582, 9 pages.

30. G. Neupane, R.J. Donahoe, Y. Arai, Chemical Geology, 2014, 368, 31.

31. A. Szentes, G. Horvath, C., Varga, G. Harrach, Hungarian Journal of Industry and Chemistry, 2011, 39, 113.

32. E. Chevalier, M. Viana, S. Cazalbou, L. Makein, J. Dubois, D. Chulia, Acta Biomaterialia, 2010, 6, 266.

33. T. Kokubo, H. Kushitani, S. Sakka, T. Kitsugi, T. Yamamuro, Journal of Biomedical Materials Research, 1990, 24, 721.

34. C. Moisa, L.G. Vicas, M. Ganea, E.A. Levei, O. Cadar, C. Berce, Farmacia, 2018, 66, 176.

35. S.T. Ho, D.W. Hutmacher, Biomaterials, 2006, 27, 1362. 